Full Length Article

\title{
Preparation of graphene oxide modified poly(m-phenylene isophthalamide) nanofiltration membrane with improved water flux and antifouling property
}

\author{
Mei Yang ${ }^{\mathrm{a}, \mathrm{b}}$, Changwei Zhao ${ }^{\mathrm{b}, *}$, Shaofeng Zhang ${ }^{\mathrm{a}, *}$, Pei Li ${ }^{\mathrm{c}}$, Deyin Hou ${ }^{\mathrm{b}}$ \\ a School of Chemical Engineering and technology, Hebei University of Technology, Tianjin 300130, China \\ b State Key Laboratory of Environmental Aquatic Chemistry, Research Center for Eco-Environmental Sciences, Chinese Academy of Sciences, Beijing 100085, \\ China \\ ${ }^{\mathrm{c}}$ College of Materials Science and Engineering, Beijing University of Chemical Technology, No.15 Beisanhuandong Road, Chaoyang District, Beijing 100029., \\ China
}

\section{A R T I C L E I N F O}

\section{Article history:}

Received 25 July 2016

Received in revised form 9 October 2016

Accepted 12 October 2016

Available online 13 October 2016

\section{Keywords:}

Graphene oxide

Poly (m-phenylene isophthalamide) (PMIA) membrane

Anti-fouling

Hydrophilicity

Dye removal

\begin{abstract}
A B S T R A C T
Poly (m-phenylene isophthalamide)/graphene oxide (PMIA/GO) composite nanofiltartion (NF) membranes were prepared via a facile phase inversion method. Structures, surface properties and hydrophilicities of the membrane were analyzed using FT-IR, XPS, AFM, SEM, water contact angle and Zeta-potential measurements. FTIR spectra indicated the existence of hydrophilic carboxylic acid and hydroxyl groups in the GO molecules. SEM pictures revealed the large and finger-like micro-voids formed in the sublayer of the NF membranes after adding GO. The zeta-potential and water contact angle results proved that PMIA/GO composite membranes had more negatively charged and greater hydrophilic surfaces. The pure water flux of the PMIA/GO (0.3 wt\% GO) composite membrane $\left(125.2\left(\mathrm{~L} / \mathrm{m}^{2} / \mathrm{h}\right)\right)$ was 2.6 times as high as that of the pristine PMIA NF membrane $\left(48.3\left(\mathrm{~L} / \mathrm{m}^{2} / \mathrm{h}\right)\right)$ at $0.8 \mathrm{MPa}$ with slightly higher rejections to all tested dyes and better fouling resistance to bovine serum albumin (BSA). This study gave an effective method for preparing composite PMIA NF membranes with high water flux and excellent antifouling property, which showed potential application in water treatment.
\end{abstract}

(C) 2016 Elsevier B.V. All rights reserved.

\section{Introduction}

Membrane separations, as an environmentally friendly technology, have been rapidly developed in different separation processes for decades [1-5]. Among them, nanofiltration (NF) fills the gap between ultrafiltration (UF) and reverse osmosis (RO) with major advantages of higher flux and lower operating pressure than RO membranes and better rejections to divalent salts and lower molecular weight matters than UF membranes [6]. Therefore, NF has a wide exploit in water purification [7], food industry [8], dye removal[9] and desalination[10] etc. Recently, the rapid development of nanomaterials has infiltrated several of fields including membrane separation $[11,12]$. Due to the unique performance and nanoscale dimensions of nanomaterials, they are widely utilized in material modification and other aspects [13-17]. The latest attention toward nanomaterials is paid to graphene, a single 2D carbon sheet with one-atom-layer thickness [18]. Graphene has notably

\footnotetext{
* Corresponding authors.

E-mail addresses: zhaocw@rcees.ac.cn (C. Zhao), shfzhang@hebut.edu.cn (S. Zhang).
}

high surface area, good mechanical strength and a nearly frictionless surface [19-21]. However the hydrophobic nature limits its applications in water separation membranes. Whereas, graphene oxide (GO), as a derivative of graphene which includes lots of functional groups such as hydroxyl, carbonyl, epoxy and carboxyl groups [22-24], is very hydrophilic and water molecules pass through the nano-channels formed by GO packing very fast [25]. These properties motivate membrane researchers to incorporate GO into membranes and explore their separation performance.

Previous studies showed that membranes prepared from pure GO were unstable in water [26]. Therefore, GO must be added into a polymer matrix to overcome this problem [27-29]. Compared to other methods, blending has some advantages such as: simple, good reproducibility, mild preparation conditions and capability for industrialization. Literature results indicated that the physical capability of host polymers to GO could be enhanced by properly blending GO in the polymer dope solution, even at very low doping contents [30-32]. Also, due to the atomically smooth surface of graphene and the hydrophilic nature of GO, incorporation GO into a polymer matrix would increase the hydrophilicity of the membrane surface [33]. Moreover, blending GO would reduce adsorption of proteins on the membrane surface, thus alleviat- 
Table 1

Characteristics of the dyes.

\begin{tabular}{|c|c|c|c|c|}
\hline Dye & Abbreviation & Molecular & Molecular weight & Charge number \\
\hline Cationic Red X-GTL & $\mathrm{CR}$ & $\mathrm{C}_{20} \mathrm{H}_{28} \mathrm{ClN}_{5} \mathrm{O}_{6} \mathrm{~S}$ & 502.50 & +2 \\
\hline Acid Red & $\mathrm{AR}$ & $\mathrm{C}_{20} \mathrm{H}_{12} \mathrm{~N}_{2} \mathrm{Na}_{2} \mathrm{O}_{7} \mathrm{~S}_{2}$ & 502.43 & -2 \\
\hline Reactive Yellow & RY & $\mathrm{C}_{21} \mathrm{H}_{15} \mathrm{ClN}_{8} \mathrm{O}_{7} \mathrm{~S}_{2}$ & 636.97 & -2 \\
\hline
\end{tabular}

Table 2

Molecular structure of dyes.

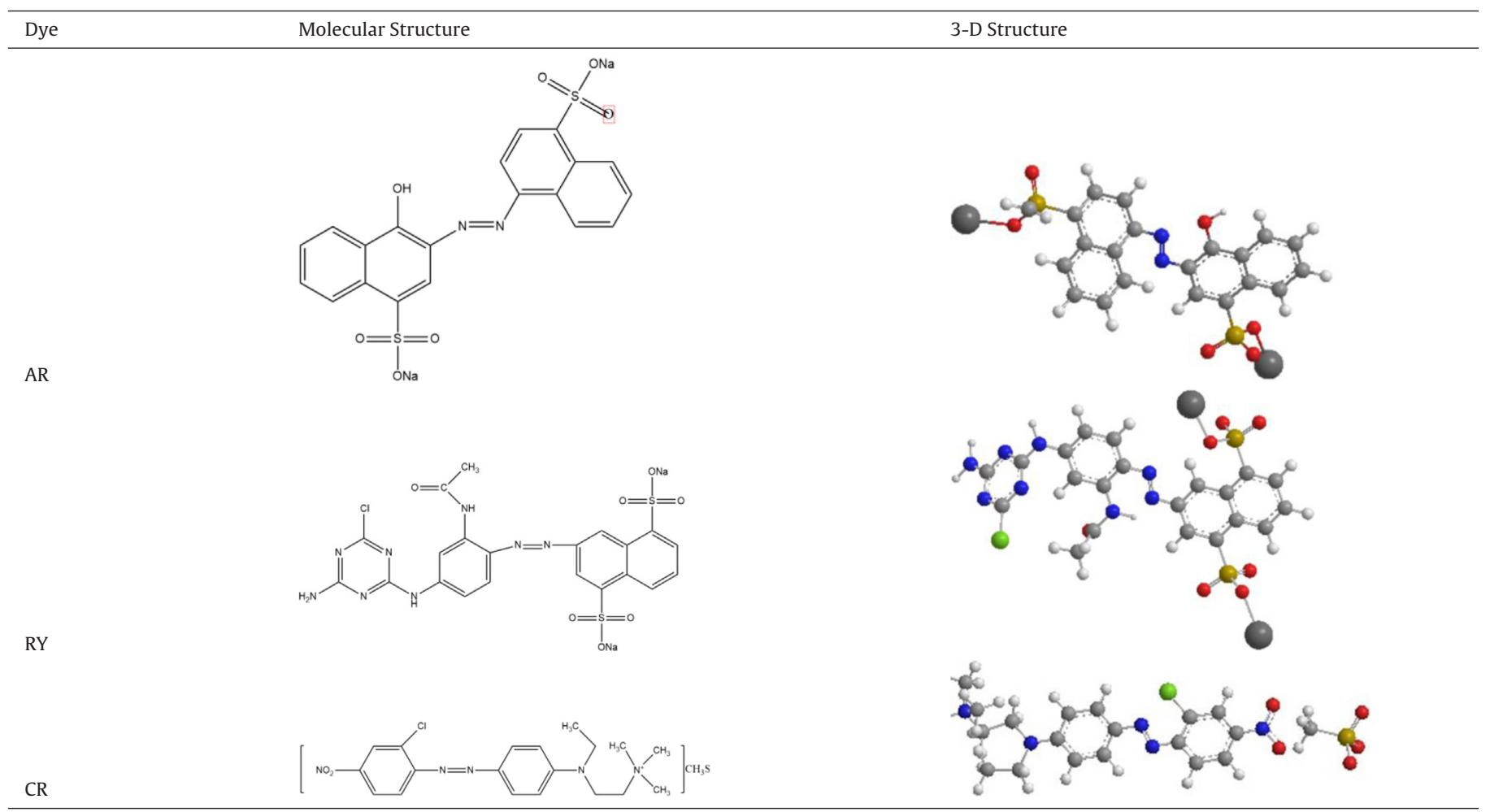

ing fouling of membrane $[34,35]$. Jin et al. prepared the PES/GO composite ultrafiltration membranes by phase inversion method [35]. Both the hydrophilicity and water flux of the modified PES membranes were improved. Wang et al. fabricated PVDF/GO organic-inorganic UF membranes [36]. The resulting membranes have higher hydrophilicity and better water flux recover rate. Ganesh et al. prepared PSF/GO composite membrane that had excellent salts rejection and high pure water flux [37]. In a word, membranes which were prepared by first blending GO in the polymer dopes and then undergoing phase inversion protocol exhibited higher water flux and improved antifouling properties.

Poly (m-phenylene isophthalamide) (PMIA) has great thermal resistivity $\left(\mathrm{T}_{\mathrm{g}} 270^{\circ} \mathrm{C}\right)$, good chemical stability, elongation at break and toughness as well as high mechanical strength, which explains PMIA is an outstanding membrane material [38-40]. Wang et al. fabricated a PMIA hollow fiber NF membrane that could effectively remove a persistent organic pollutant, perfluorooctane sulfonate (PFOS), from water [41]. In another study, Huang et al. developed a phase inversion procedure for fabrication of PMIA NF membranes with high performance in applications of dye purification and desalination [10]. However, the water fluxes of these PMIA asymmetric NF membranes were relatively low.

Based on the literature studies, GO could efficiently improve the water flux and antifouling properties of water separation membranes. Therefore, at present research, GO was incorporated into PMIA polymer dope and the PMIA/GO NF membranes were fabricated using phase inversion. The fouling resistance and separation performance of the PMIA/GO membranes have been investigated.
Structures and physicochemical properties of the membranes were determined by XPS, AFM, SEM, contact angle and zeta potential measurements. NF properties were evaluated by rejection of Cationic Red X-GTL, Acid Red and Reactive Yellow, while antifouling performance of the PMIA/GO NF membranes was also tested.

\section{Materials and methods}

\subsection{Materials}

PMIA whose chemical structure was shown in Fig. 1 was produced by Dupont (USA). LiCl (>95\%) was obtained from Tianjin Guangfu Research Institute of Fine Chemical Engineering (China). $N, N$-dimethylacetamide (DMAC, $>99 \%$ ) was supplied by Shanghai Jingwei Chemical Co.,Ltd (China). GO was purchased from Nanjing XFNANO technology Co., Ltd (China). The dye, Cationic Red X-GTL, Acid Red and Reactive Yellow were obtained from Sigma-Aldrich (Shanghai) (the characteristics and molecular structure of the three dyes was shown in Table 1 and 2). Bovine serum albumin (BSA) was obtained from Sinopharm Chemical Reagent Co. Ltd. (China).

\subsection{Membrane preparation}

The PMIA/GO composite membranes were fabricated by the phase inversion method. Table 3 lists the compositions of dope solutions for preparing membranes. First, certain amount of GO was added into DMAC. Then the solution was sonicated in an ultrasonic cell disrupter about 40 min. After sonication, PMIA and $\mathrm{LiCl}$ were 


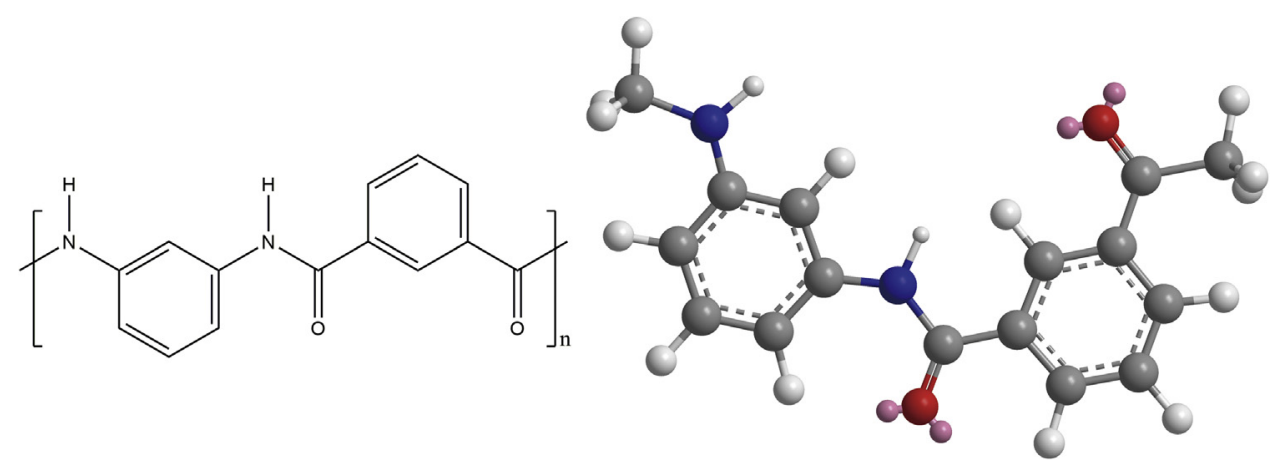

Fig. 1. Chemical structure and three-dimensional crystal structure of PMIA.

Table 3

The compositions of dope solutions.

\begin{tabular}{llll}
\hline membrane & wt(GO)\% & wt(LiCl)\% & wt(PMIA)\% \\
\hline PMIA & 0 & 5 & 20 \\
PMIA/GO-1 & 0.05 & 5 & 20 \\
PMIA/GO-2 & 0.1 & 5 & 20 \\
PMIA/GO-3 & 0.3 & 5 & 20 \\
PMIA/GO-4 & 0.5 & 5 & 20
\end{tabular}

added in the DMAC/GO solution at $80^{\circ} \mathrm{C}$ and followed by $12 \mathrm{~h}$ stirring to obtain a homogenous solution. At last, in order to eliminate all air pocket, the casting solution was degassed in vacuum for $24 \mathrm{~h}$ before casting. The dope solution was casted on a glass plate by self-made casting knife. Then the glass plate was immediately put into a distilled water bath to induce the phase inversion process at $25^{\circ} \mathrm{C}$ after evaporated two minutes at $80^{\circ} \mathrm{C}$. The nascent membranes were further placed in distilled water for at least $24 \mathrm{~h}$ to remove the remaining DMAC solvent and $\mathrm{LiCl}$.

\subsection{GO characterizations}

The chemical structures and morphologies of the GO were tested by Fourier transform infrared spectroscopy-attenuated total reflectance (FTIR-ATR, Thermo Fisher Scientific, USA, Nicolet 8700), Scanning electron microscopy (SEM, Hitachi Ltd, Japan, SU-8020), X-ray diffraction (XRD, PANalytical, Netherlands, X'Pert PRO MPD).

\subsection{Characterization of the prepared membranes}

\subsubsection{X-ray photoelectron microscopy (XPS)}

The surface elemental compositions of all membranes were monitored using X-ray photoelectron spectroscopy (XPS) (Kratos Analytical Ltd., UK). XPS PEAK software (version 4.1) was used to analyze and fit the XPS spectra with reference to the $\mathrm{C} 1 \mathrm{~s}$ binding energy at $284.8 \mathrm{eV}$. The XPS spectra were obtained by subtracting the background spectra and analyzed by the Gaussian-Lorentzian peak shape method.

\subsubsection{Scanning electron microscopy (SEM)}

The composite membranes were monitored using SEM to observe their structures and morphologies. The membrane samples were cut into thin pieces and quenched in liquid nitrogen for $60-90$ s and subsequently broken to acquire the natural crosssection structure of the membrane. After that, the samples were dried in vacuum oven and stuck on the sample stage by a conductive type and sprayed gold by a HITACHI E-1010 ion sputtering coater.

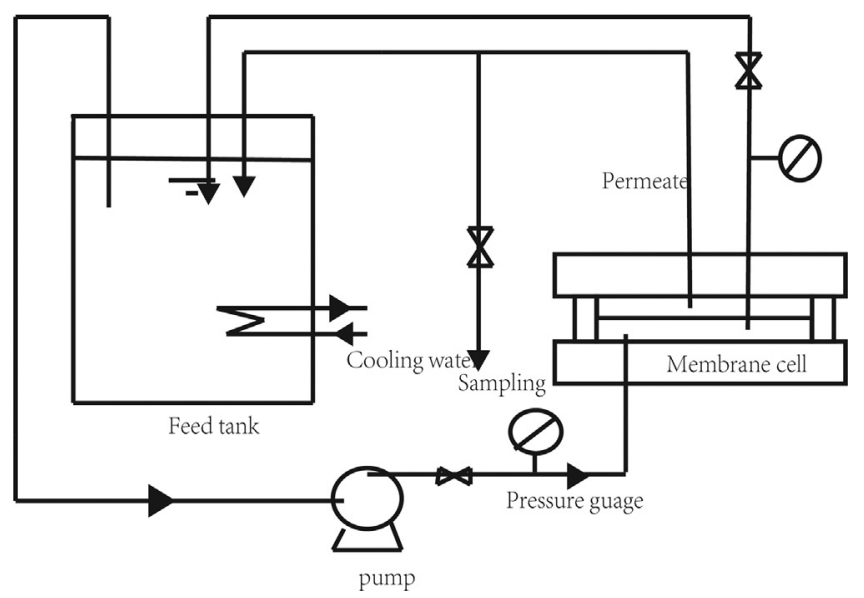

Fig. 2. A schematic diagram of the cross-flow NF membrane separation device used in this research.

\subsubsection{Zeta potential measurement}

A Zetasizer (Nano ZS 90 series, Malvern, UK) was used for measuring the zeta potentials of prepared membranes at $25 \pm 0.1^{\circ} \mathrm{C}$. A $0.001 \mathrm{~mol} / \mathrm{L} \mathrm{NaCl}$ solution was used as the electrolytic solution and the solution $\mathrm{pH}$ values were controlled in the range of 2-9 by adding certain amount of $0.1 \mathrm{M} \mathrm{NaOH}$ or $0.1 \mathrm{M} \mathrm{HCl}$ solutions.

\subsubsection{Contact angle measurement}

A contact-angle measurement apparatus (OCA 15EC, Germany Dataphysics company) was used for testing the water contact angle (WCA) of all membrane surfaces at $25^{\circ} \mathrm{C}$ and a relative humidity of $40 \%$. In order to reduce experimental error, each membrane samples were measured at least three times and the average value was referred to as the sample WCA.

\subsubsection{Membrane surface morphologies}

Atomic force microscopy (AFM) images were obtained using a Multimode SPM equipped with a J-type piezoelectric scanner and a Nanoscope III controller (Digital Instruments, USA). The sample was fixed on a specimen holder and scanned with a silicon cantilever tip in a tapping mode to obtain the surface topography image. An area of $5 \mu \mathrm{m} \times 5 \mu \mathrm{m}$ was scanned and the surface average arithmetic roughness $\left(R_{a}\right)$, the root mean square roughness $\left(R_{q}\right)$ and the root peak-to-valley distance $\left(R_{z}\right)$ were calculated.

\subsection{Membrane performance tests}

The solute rejection and pure water flux of membranes was analyzed using a cross-flow nanofiltration system as shown in Fig. 2 [42,43]. The pure water flux measure was conducted at $25^{\circ} \mathrm{C}$ and $0.8 \mathrm{MPa}$ and the effective area of the membrane was $139 \mathrm{~cm}^{2}$. 
Before test, each membrane was compressed at $1 \mathrm{MPa}$ for $60 \mathrm{~min}$ by distilled water and then the pressure was reduced to $0.8 \mathrm{MPa}$ in order to obtain a steady flux. The membrane water flux $\mathrm{J}\left(\mathrm{L} / \mathrm{m}^{2} \mathrm{~h}\right)$ was estimated using the following equation:

$\mathrm{J}=\mathrm{V} / \mathrm{A} \Delta \mathrm{t}$

where $\mathrm{V}$ is the volume of the permeate pure water $(\mathrm{L}), \Delta \mathrm{t}$ is the operation time $(\mathrm{h})$, and $A$ is the effective membrane area $\left(\mathrm{m}^{2}\right)$.

\subsection{The application of the membrane in dye water treatment}

A $50 \mathrm{mg} / \mathrm{L}$ dye solution was utilized as the feed solution of the same filtration equipment. The ultraviolet-visible spectrophotometer (DR-5000) from the America HACH Company was used for analyzing the concentrations of dye in the permeate solution. The rejection (R) to dye was calculated using Eq. (2).

$\mathrm{R}=1-\frac{\mathrm{C}_{\mathrm{p}}}{\mathrm{C}_{\mathrm{f}}}$

where $C_{f}$ represents the solute concentrations in the feed solutions and $C_{p}$ is the solute concentration in the permeate.

\subsection{Anti-Fouling and anti-corrosive evaluation}

A $5000 \mathrm{mg} / \mathrm{L}$ bovine serum albumin (BSA) solution was utilized to test the anti-fouling performance of the fabricated membranes. First, pure water flux $\mathrm{J}_{\mathrm{w} 1}\left(\mathrm{~L} / \mathrm{m}^{2} \cdot \mathrm{h}\right)$ of the membrane was determined after $120 \mathrm{~min}$ pure water permeation test at $25^{\circ} \mathrm{C}$ and $0.8 \mathrm{MPa}$. Then, the feed was replaced by the $5000 \mathrm{ppm}$ BSA solution, and the water flux was recorded at $\mathrm{PH}=7$ and same operation condition for another $120 \mathrm{~min}$. After that, the membrane surface was flushed with distilled water for $20 \mathrm{~min}$ and then the pure water flux was tested again at the same operation condition and coded as $\mathrm{J}_{\mathrm{w} 2}\left(\mathrm{~L} / \mathrm{m}^{2} \cdot \mathrm{h}\right)$. Then, the flux recovery ratio (FRR) was computed using Eq. (3) $[44,45]$.

$\mathrm{FRR}=\left(\frac{J_{w, 2}}{J_{w, 1}}\right) \times 100 \%$

Alkali and acid solution was utilized to test the anti-corrosive performance of the fabricated membranes and the solution $\mathrm{pH}$ values were controlled in the range of $1 \sim 13$ by adding certain amount of $\mathrm{NaOH}$ or $\mathrm{HCl}$ solutions. The membrane was soaked into the solution which their $\mathrm{PH}=1,3,5,9,11,13$. After $12 \mathrm{~h}$, the changes of membranes water flux were measured before and after immersion.

\section{Results and discussion}

\subsection{Characterization of GO nanoplates}

Several testing methods was carried out to understand the properties of GO and its effects to the performances of the composited membrane [27]. The FT-IR test was carried out in order to study the chemical structure of GO. Fig. 3(a) illustrates the Fourier trans-form infrared spectrum of GO. Two peaks at $1376 \mathrm{~cm}^{-1}$ and $3345 \mathrm{~cm}^{-1}$ are corresponding to the deformation vibration and stretching vibration of $\mathrm{O}-\mathrm{H}$ group in $\mathrm{GO}[37,46]$. The peak at $1729 \mathrm{~cm}^{-1}$ represents the stretching vibration of $\mathrm{C}=\mathrm{O}$ group, and peaks at $1051 \mathrm{~cm}^{-1}$ and $1224 \mathrm{~cm}^{-1}$ represents the $\mathrm{C}=0$ stretching vibration of the epoxy alkyl group. The peak at $1626 \mathrm{~cm}^{-1}$ corresponds to the vibration of aromatic of $\mathrm{C}=\mathrm{C}$ and the vibrations of the adsorbed water molecules [47,48]. Fig. 3 (b) shows GO in $2 \theta \approx 11^{\circ}$ appeared a great strength diffraction peaks, which can determine the GO were effectively functional and it can be used for modification. A typical lamellar morphology of GO with a myriad of wrinkles and edge curl is observed in Fig. 3(c). Since GO has large aspect ratio, the GO exhibits natural folding morphologies in the solvent to reduce its large surface energy.

\subsection{Characterization of graphene oxide membranes}

\subsubsection{Chemical characterizations}

The typical C I s XPS spectra of PMIA and PMIA/GO membranes are shown in Fig. 4. For pristine PMIA membrane (Fig. 4(a)), three peaks located at $284.5 \mathrm{eV}, 283.3 \mathrm{eV}$ and $286.9 \mathrm{eV}$ were deconvoluted attributed to carbon bond structures of $\mathrm{C}-\mathrm{C}, \mathrm{C}-\mathrm{H}$ and $\mathrm{C}-\mathrm{N} / \mathrm{C}=\mathrm{O}[28,49,50]$. When $0.3 \mathrm{wt} \% \mathrm{GO}$ was blended to PMIA membrane, five relatively larger peaks appeared as shown in Fig. 4(b) which were attributed to carbon bond structures of $\mathrm{C}-\mathrm{H}(283.3 \mathrm{eV})$, $\mathrm{C}-\mathrm{N} / \mathrm{C}=\mathrm{O}(286.9 \mathrm{eV}), \mathrm{C}-\mathrm{C}(284.5 \mathrm{eV}), \mathrm{C}-\mathrm{OH}(286.1 \mathrm{eV})$ and $\mathrm{C}-\mathrm{O}-\mathrm{C}$ $(285.2 \mathrm{eV})$ of which the additional $\mathrm{C}-\mathrm{OH}$ and $\mathrm{C}-\mathrm{O}-\mathrm{C}$ groups should be from the GO molecules $[28,47,51]$. Hence, the XPS spectra proved the existence of GO molecules in the membrane.

\subsubsection{Morphologies of the GO embedded PMIA membranes}

The composite membranes were monitored using SEM was used for observing the structures and morphologies of the composite membrane. SEM figures of the membrane surface and crosssection morphologies are displayed in Fig. 5. From Fig. 5(a)-(d), we can see clearly that the membrane surfaces are quite smooth and no aggregations of the GO nanoplate are formed on membrane surfaces. Fig. 5(a1,a2)-(e1,e2) shows the SEM membrane cross-section morphologies. Both PMIA and PMIA/GO composite membranes have a porous sub-layer and dense skin layer. The thin and compact skin layer results in high rejection of the membrane. While the microporous sub-layer provides mechanical strength as well as low resistance to water permeation. Comparing Fig. 5(a1,a2)-(b1,b2-e1,e2), significant differences in the sublayers' structures are observed. Membrane formed by pure PMIA shows a sublayer full of sponge like structure but no finger-like microvoids. Whereas, others formed by PMIA/GO mixed dopes all have finger-like micro-voids. And the sizes of the finger-like micro-voids increase at higher GO contents. This phenomenon can be explained by the accelerating solvent/nonsolvent exchange rate induced by $\mathrm{GO}$ in the phase inversion process. Since GO containing a large number of hydrophilic functional groups, blending GO into the PMIA dope promotes the diffusion of water from the coagulant bath to the dope solution. During the phase inversion process, the micro-void is initially formed by nucleation and then grows in liquid-liquid phase separation. With the increase in the GO concentration, the polymer dope becomes more hydrophilic. Water diffuses faster into the polymer lean phases of the polymer dope. This leads to the larger size of the polymer lean phases and the formation of big finger-like micro-voids.

As the GO concentration increases to $0.5 \mathrm{wt} \%$, some transverse bores are observed in the membrane sublayer as highlighted in Fig. 5(e1,e2). The formation of these horizontal oriented pores may be due to the hydrophilic nature and the high aspect ratio of the GO molecule. The hydrophilic nature of GO makes water intend to surround GO nanosheet and form polymer-lean phase. The high aspect ratio of GO leads to the water molecules flowing along the GO surface and the orientations of the resulting micro-voids are parallel to the GO surfaces. It is rational to assume that the orientations of GO nanosheets are random in the polymer dopes. However, when the content of GO increases, the amount of transverse orientated GO increases. Therefore, more and bigger transverse bores are formed in the membrane sublayer as shown in Fig. 5(e1,e2). The presence of these transverse bore may interrupt the communication of the original finger hole and the water flux of the membrane may be less.

Table 4 illustrated the $\mathrm{R}_{\mathrm{a}}, \mathrm{R}_{\mathrm{q}}$ and $\mathrm{R}_{\mathrm{z}}$ of the pristine PMIA membranes and PMIA/GO composite membranes. The results reveal 

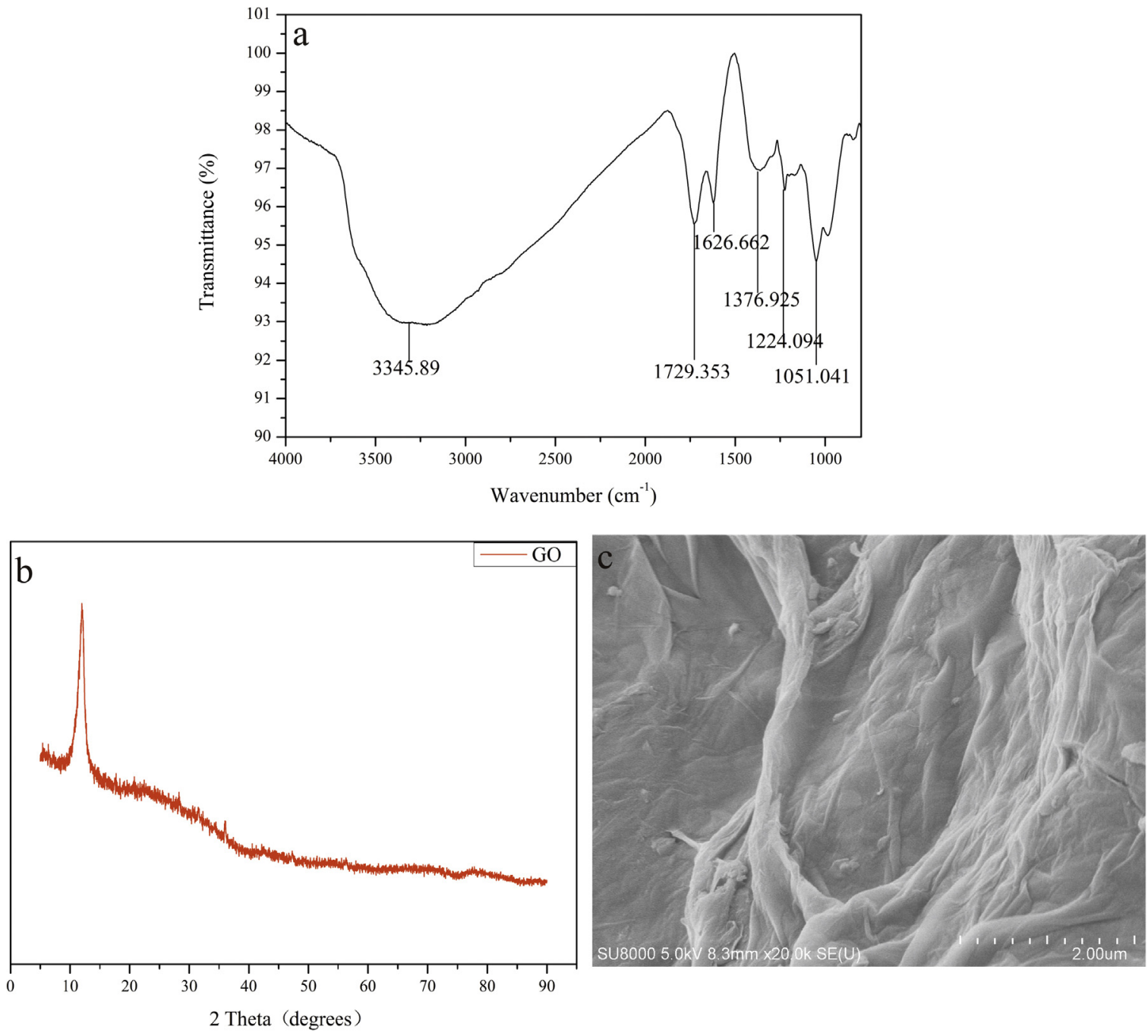

Fig. 3. (a) the FTIR spectra, (b) XRD spectra, and (c) SEM picture of GO.
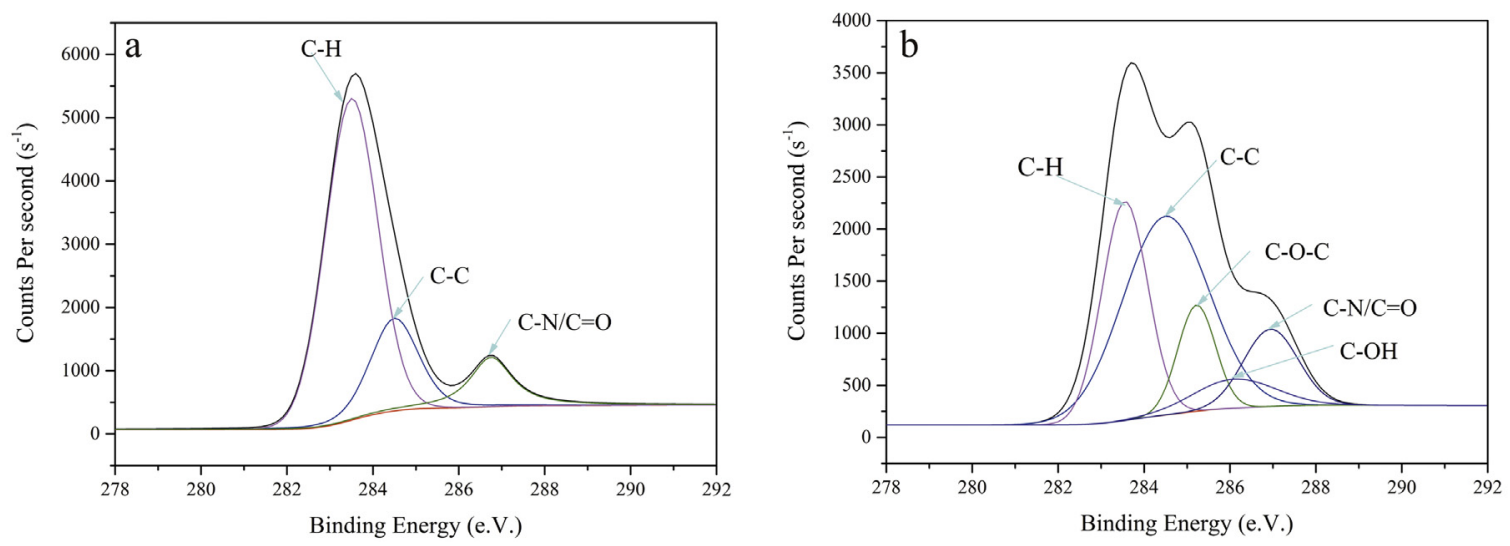

Fig. 4. Comparison of the high-resolution XPS C 1 s spectrum for (a) pure PMIA, and (b) PMIA/GO-3.

Table 4

Surface roughnesses of PMIA, PMIA/GO-1, PMIA/GO-2,PMIA/GO-3 and PMIA/GO-4.

\begin{tabular}{llll}
\hline Membrane ID & $R_{a}(\mathrm{~nm})$ & $R_{\max }(\mathrm{nm})$ & $R_{q}(\mathrm{~nm})$ \\
\hline PMIA & 4.367 & 35.371 & 5.252 \\
PMIA/GO-1 & 1.601 & 19.430 & 2.037 \\
PMIA/GO-2 & 1.775 & 27.372 & 2.265 \\
PMIA/GO-3 & 2.810 & 65.380 & 3.739 \\
PMIA/GO-4 & 3.791 & 30.221 & 4.458 \\
\hline
\end{tabular}

that the pristine PMIA membrane has a higher roughness than PMIA/GO composite membranes, with $\mathrm{R}_{\mathrm{a}}=4.367 \mathrm{~nm}, \mathrm{R}_{\mathrm{q}}=5.252 \mathrm{~nm}$ and $\mathrm{R}_{\mathrm{z}}=35.371 \mathrm{~nm}$. The surface of membrane became smooth because of low electrostatic interactions of modified carbon based nanofiller with low contents, they are regularly collocated in membrane [52]. On the other hand, the roughness of PMIA/GO composite membranes is enhanced as the GO content increases to $0.5 \mathrm{wt} \%$. This phenomenon may be because of during the phase inversion pro- 

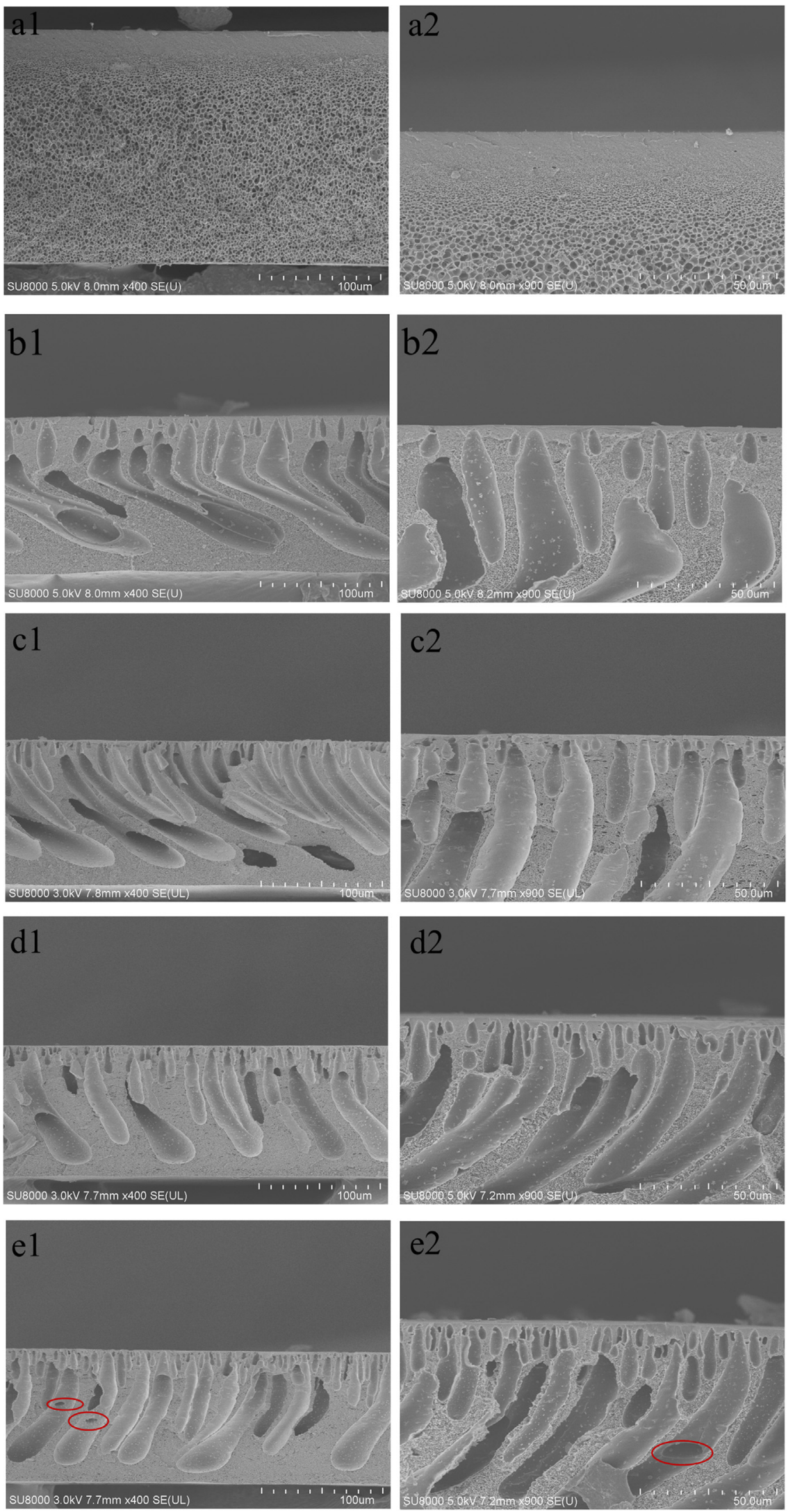

Fig. 5. SEM surface photographs of (a) pure PMIA membrane (b) PMIA/GO-1, (c) PMIA/GO-2 and (d) PMIA/GO-3 composite membranes; SEM cross-section photographs of $(\mathrm{a} 1, \mathrm{a} 2)$ pure PMIA membrane (b1,b2) PMIA/GO-1, (c1,c2) PMIA/GO-2, (d1,d2) PMIA/GO-3 and (e1,e2) PMIA/GO-4 composite membranes. 

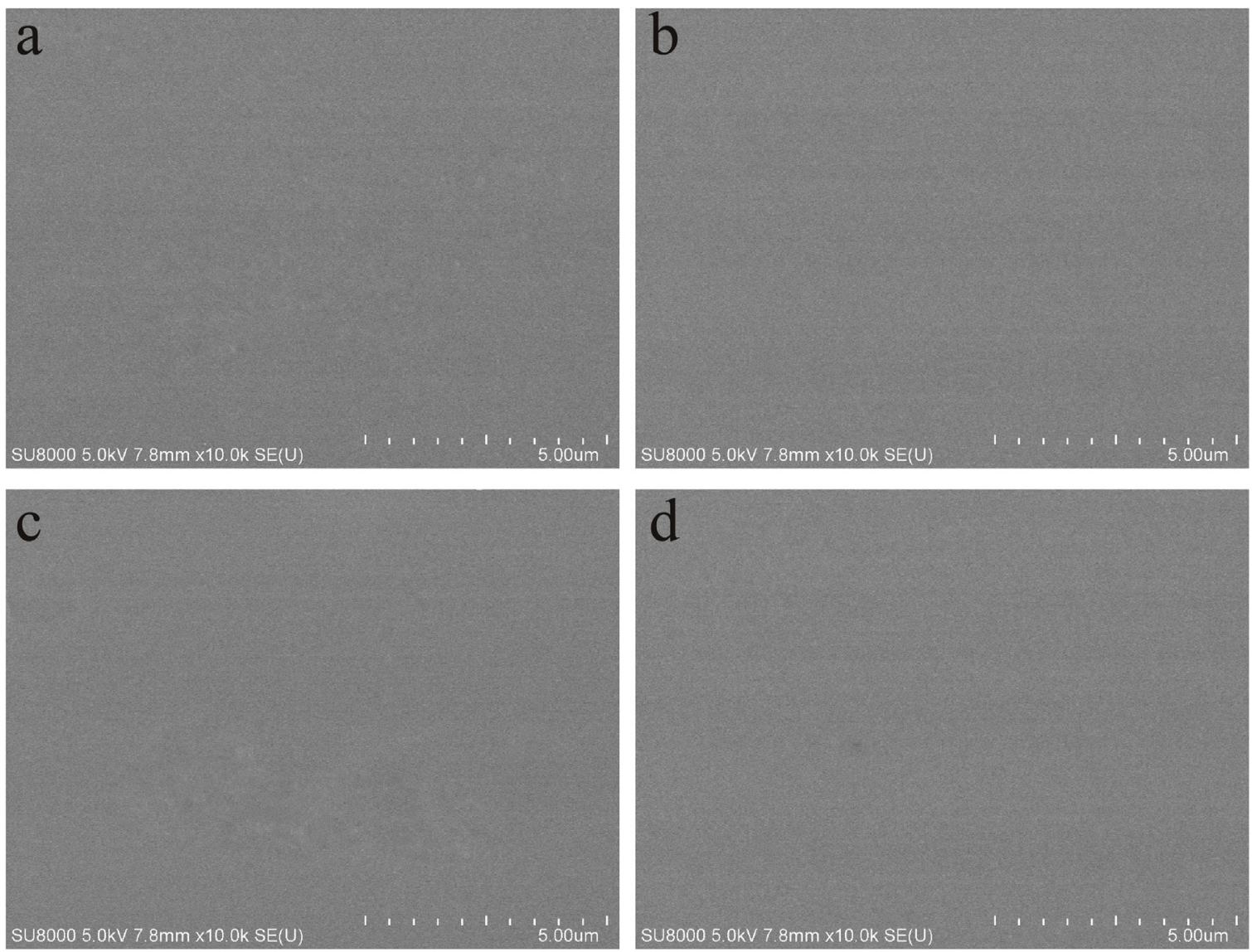

Fig. 5. (Continued)

cess the hydrophilic performance of GO caused the fast exchange of non-solvent and solvent. However, even added $0.5 \mathrm{wt} \% \mathrm{GO}$, the average roughness of pure PMIA membrane is higher than composite membrane. A similar result was also described by Ganesh et al. for GO/PSF membranes [37] and Zinadini et al. [53] for GO composite PES membranes. Fig. 6 gives the AFM images of the prepared membranes surfaces. The dark regions represent holes or valleys and the brightest regions indicate the highest places of the membrane surface. When GO is incorporated, the large valleys and peaks are substituted by more small peaks and valleys, which leads to sharper and denser asperities on the PMIA/GO composite membrane surfaces than the pristine PMIA membrane surface [54].

\subsubsection{Hydrophilicity and pure water flux}

As shown in Fig. 7(a), the WCA decreases with the increase in the GO concentration of PMIA/GO composite membrane. The $0.3 \mathrm{wt} \%$ PMIA/GO composite membrane has the lowest WCA of $62^{\circ}$. The decreased WCA indicates that the PMIA/GO composite membranes are more hydrophilic than the pristine PMIA membrane. However, when the membrane was added $0.5 \mathrm{wt} \% \mathrm{GO}$, the WCA of PMIA/GO composite membrane have slightly increased. This may be due to agglomeration and reduced effective surfaces of the nanoplates in the high GO contents, which lead to surface hydrophilic functional group of the membrane decresed, then the WCA of the membrane increased.

The higher hydrophilicity of the PMIA/GO composite membranes matches their higher water fluxes. The water fluxes of the composite membranes with $0.05 \mathrm{wt} \% \backslash 0.1 \mathrm{wt} \% \mathbf{} 0.3 \mathrm{wt} \%$ and $0.5 \mathrm{wt} \%$ GO are 2, 2.2, 2.6 and 2.4 times as high as that of pure PMIA membrane, respectively. GO has a large amount of hydrophilic groups, which increases the hydrophilicity of the mem- brane and internal pore channel surface. By increasing the graphene oxide content, the composite membrane becomes more and more hydrophilic. Zinadini et al. fabricated a novel mixed matrix PES membrane. The water fluxes of unfilled PES membrane is 8.2 $\left(\mathrm{L} / \mathrm{m}^{2} / \mathrm{h}\right)$ at $0.4 \mathrm{MPa}$, after blending $0.5 \mathrm{wt} \% \mathrm{GO}$, the water fluxes of composite membranes are $20.4\left(\mathrm{~L} / \mathrm{m}^{2} / \mathrm{h}\right)$ at $0.4 \mathrm{MPa}$ [53]; Chang et al. prepared PVDF ultrafiltration membrane. The water fluxes of pure PVDF membrane is about $40\left(\mathrm{~L} / \mathrm{m}^{2} / \mathrm{h}\right)$ and the water fluxes of PVDF/GO composite membranes become about $81\left(\mathrm{~L} / \mathrm{m}^{2} / \mathrm{h}\right)$ at $0.1 \mathrm{MPa}$ [33]; Genesh et al. fabricated polysulfone mixed matrix membrane. The water fluxes of PSF/GO (2000 ppm) membrane are $25\left(\mathrm{~L} / \mathrm{m}^{2} / \mathrm{h}\right)$ at $0.6 \mathrm{MPa}$. However, the water flux of $0.3 \mathrm{wt} \%$ PMIA/GO composite membrane up to $125.2\left(\mathrm{~L} / \mathrm{m}^{2} / \mathrm{h}\right)$ [37]. However, the water flux of the $0.5 \mathrm{wt} \%$ PMIA/GO composite membrane is slightly lower than that of the $0.3 \mathrm{wt} \%$ composite membrane. This may be because of more GO content leads to the reunion and the formation of more transverse bores which may block the internal pore connection and hinder the water transport. Therefore, the $0.5 \mathrm{wt} \%$ PMIA/GO composite membrane shows a slightly lower water flux than that of the $0.3 \mathrm{wt} \%$ composite membrane.

\subsubsection{Membrane zeta potentials}

The zeta potentials of the pristine PMIA and 0.3 wt\% PMIA/GO composite membranes at different pH values are shown in Fig. 7(b). As $\mathrm{pH}$ increases, the zeta potentials decrease because the amide groups of PMIA membrane hydrolyzed to carboxyl groups as the alkaline of solution increase. It has been described by literature that at the entire $\mathrm{pH}$ range the $\mathrm{GO}$ can result in negative charge, since the acidic functional groups of GO result in more negatively charged membrane surface [53,55]. Fig. 7(b) proves that the 


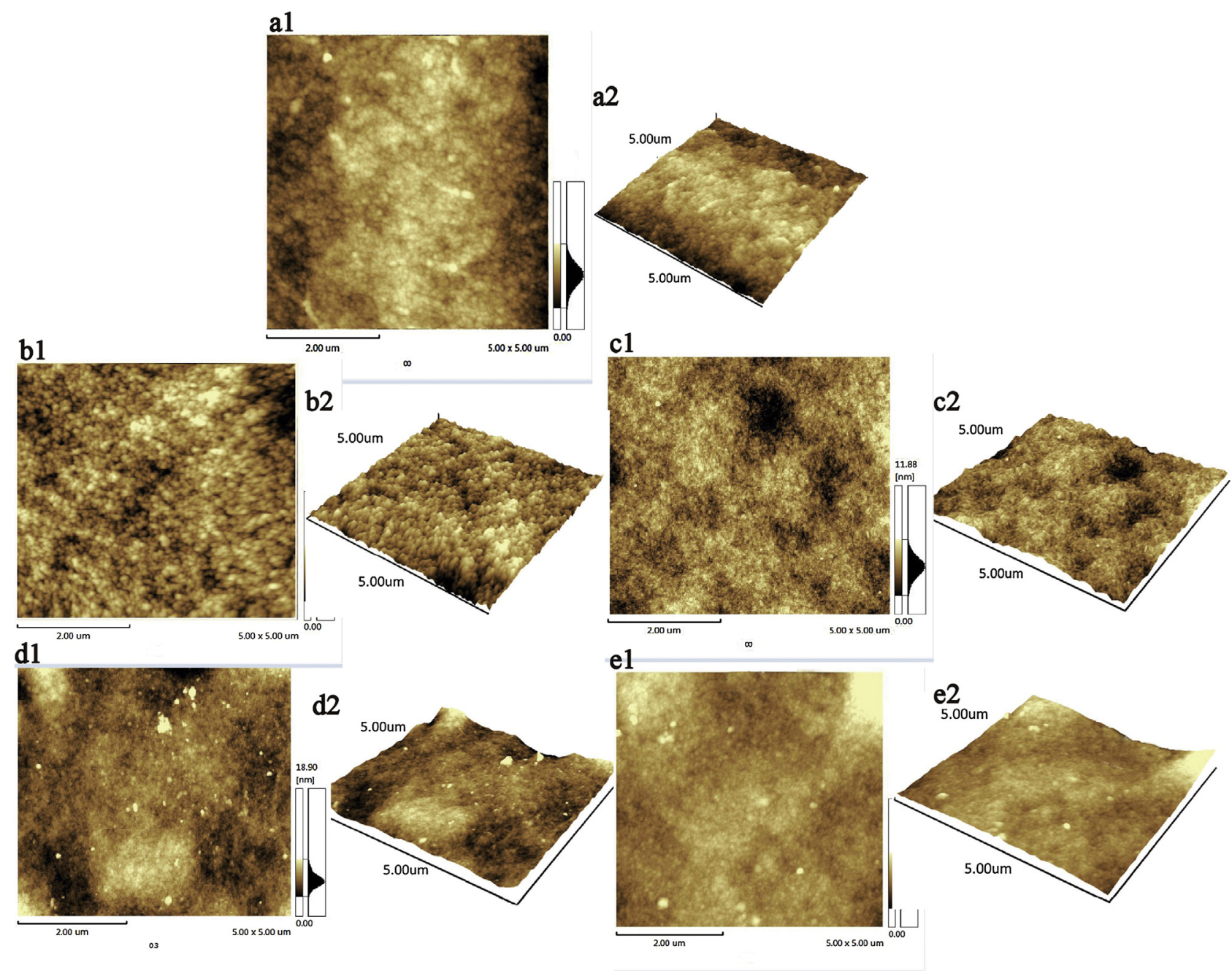

Fig. 6. Two and three-dimensional AFM surface topographies of PMIA substrate (a1, a2).
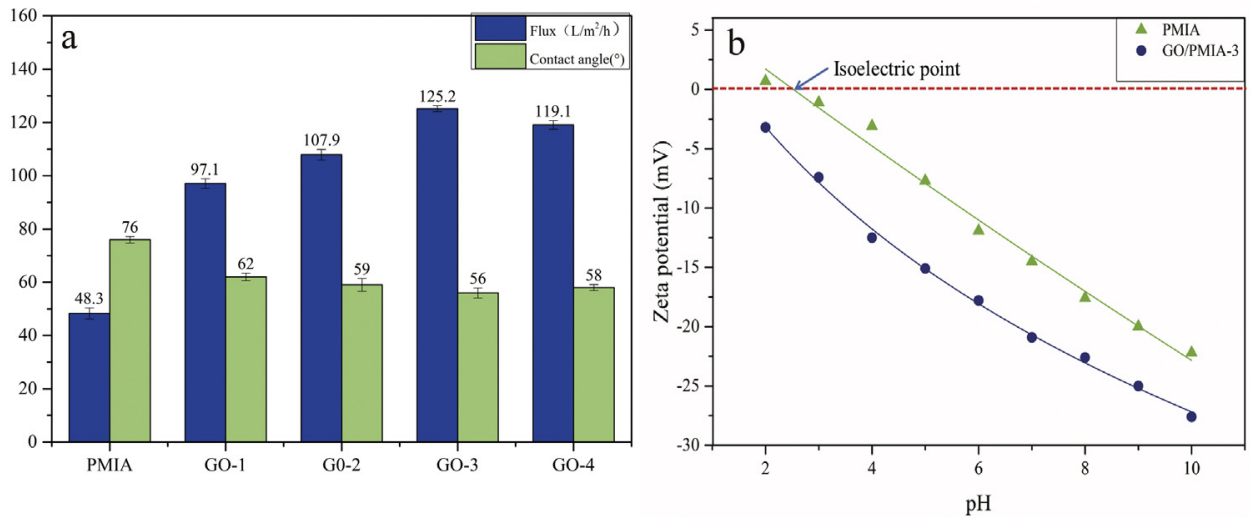

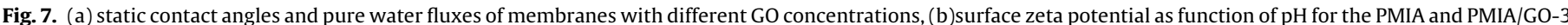
NF membranes.

PMIA/GO blended membrane is more negatively charged than the pristine PMIA membrane at the entire $\mathrm{pH}$ range.

\subsection{Membrane performance}

\subsubsection{Application of the membrane in dye water treatment}

Over the past decades, NF has a wide exploit in reliable purification. NF membrane has a low rejection on the small molecular, and the intermediates of inorganic salts and small molecules can be passed through, is the first technology choice to treat the of dye waster [56]. According to the results of prepared PMIA nanofiltration membrane in laboratory, the water flux of the membrane is high, which can intercept the range of the dye relative molecular mass, and the salt rejection is low, so the PMIA membrane can be selected as the nanofiltration membrane to remove the dye wastewater. In this experiment, the self-made PMIA nanofiltration 


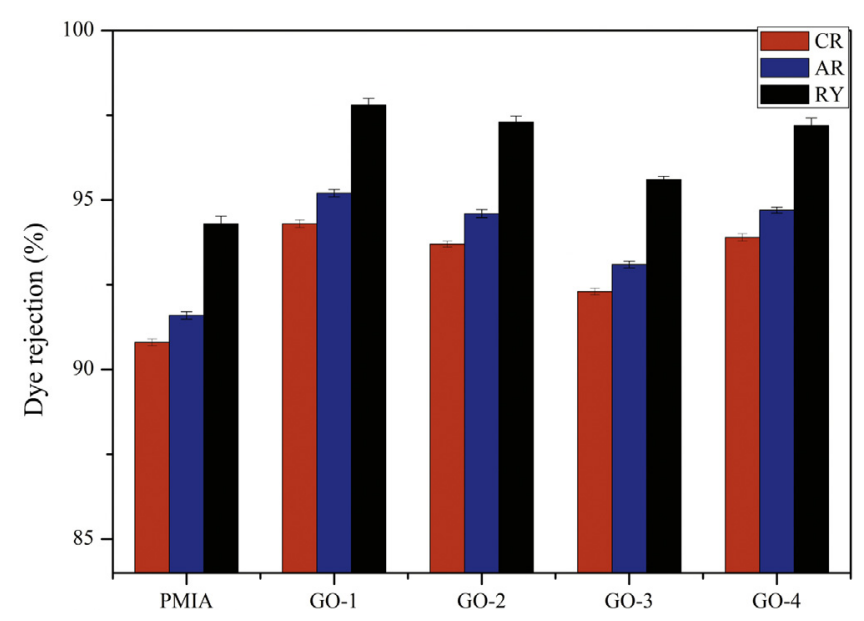

Fig. 8. Application of all the NF membrane in dye water rejection $(0.8 \mathrm{MPa}, \mathrm{pH}=6.0$, $50 \mathrm{mg} / \mathrm{L}$ dye solution, $60 \mathrm{~min}$ filtration test).

membrane was used to reject three kinds of dye solution, and provide reference for the application of PMIA nanofiltration membrane in dye wastewater treatment. The application of the membrane was showed by the dye rejection tests using a cross-flow NF equipment. Generally speaking, the separation performance of the membrane can be explained by the following theory: (1) size exclusion,(2) electrostatic repulsion. As shown in Fig. 8, both pristine PMIA membrane and composite membrane have great rejections to all three dyes and the retention decreases in an order of $R(R Y)>R$ $(A R)>R(C R)$. When $\mathrm{pH}$ value is 6 , anionic dye and membrane sur- face is negatively charged, which makes Donnan exclusion between the anionic dye and the negatively charged membrane surface to improve the retention of dye molecules. Therefore, acid red anionic dyes will be more efficient removed compared to the same molecular weight cationic dye cationic red X-GTL. In addition, reactive yellow has a relatively higher molecular weight than acid red, possesses the highest rejection rate, which is due to size exclusion effect [57]. In conclusion, the primary factor that affects the rejection of the membrane is size exclusion.

Fig. 8 also shows that the rejections to all three dyes of PMIA/GO composite membrane are higher than the pristine PMIA membranes. It has been described by literature that the GO can result in negative charge at the $2-9 \mathrm{pH}$ range (Fig. 7(b)). Due to the acidic functional groups of $\mathrm{GO}$ result in more negatively charged membrane surface, caused high rejection between the anionic dye and the negatively charged membrane surface. Among four PMIA/GO composite membranes, the trend of rejection is reversely corresponding to their water fluxes. That is, membranes with high water flux has low rejection, and vice versa [53].

\subsubsection{Antifouling and anti-corrosive performance}

Fouling is an inevitable problem in the applications of NF processes. Although the fouling mechanism is complex, the main reason for fouling formation is the hydrophobicity of the membrane surface $[53,58]$. Surface modification, polymer blend and ant other efforts have been attempted to improve the antifouling property and hydrophilicity of membrane $[26,59,60]$. As shown in Fig. 9(a), the membrane pure water fluxes are measured before and after BSA filtration to compare the fouling resistance among all membranes. When water was replaced by BSA solution, the
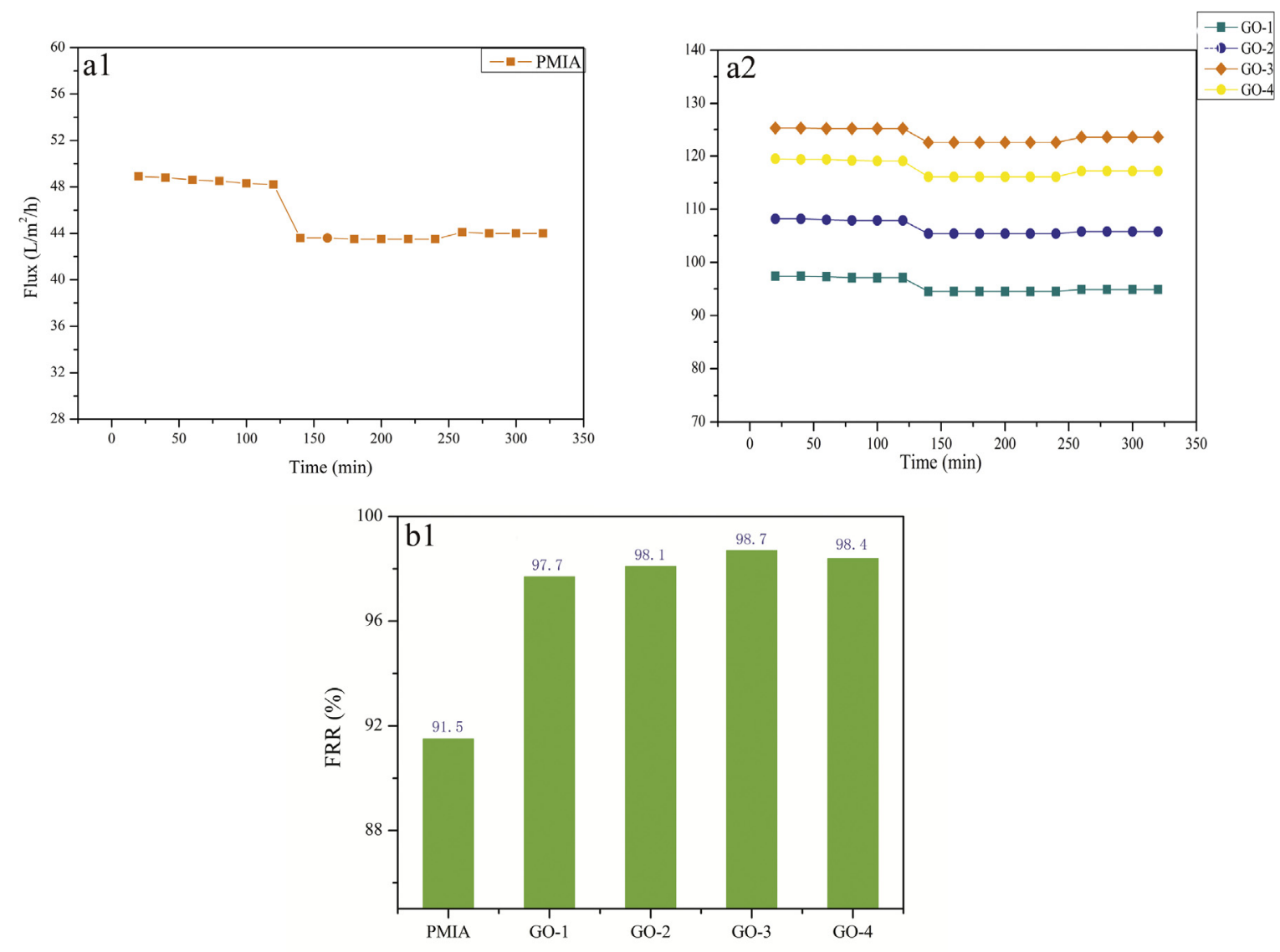

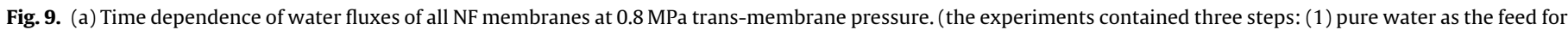

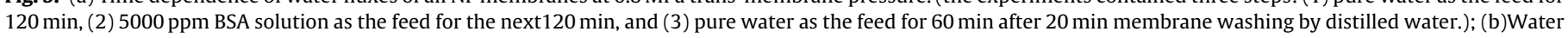
flux recovery (FRR) of all NF membranes after BSA filtration tests. 


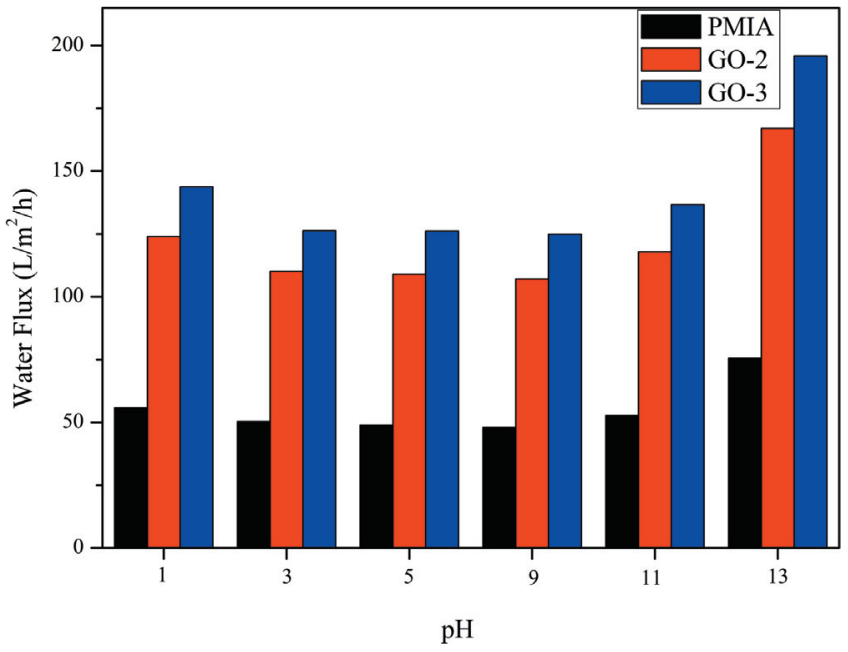

Fig. 10. Effect of the acid/alkaline content on resistance of NF membrane at $0.8 \mathrm{MPa}$ trans-membrane pressure.

water flux of pristine PMIA membrane decreased more than those of the PMIA/GO composite membranes. After the membranes was washed, the water fluxes of composite membranes recovered more than that of the pristine membrane. The FRR of the membranes are shown in Fig. 9(b). A lower FRR indicates a weak antifouling property. The FRR of all PMIA/GO composite membranes are higher than 97\%, whereas the FRR of the pristine PMIA membrane is only $91 \%$. Clearly, PMIA/GO composite membranes show better anti-fouling property which is consistent with their more hydrophilic surfaces as shown in Fig. 7(a).

With the expansion of nanofiltration membrane applications, the industrialization process have higher and higher anti-corrosive claim for nanofiltration membrane, so the anti-corrosive test of membrane is necessary. In the practical application of nanofiltration, it will inevitably face different $\mathrm{pH}$ application system, when the $\mathrm{pH}$ break out certain value, the membrane material will be eroded, which would seriously affect the performance of membrane [61]. As shown in Fig. 10, both PMIA membrane and PMIA/GO composite membrane have great anti-corrosive performance. As the $\mathrm{pH}$ strength enhanced, the water flux of membrane increased. The water flux of membrane under alkaline conditions is higher than the acidic conditions. It can be see that the PMIA membrane and PMIA/GO composite membrane can remain chemically stable in a wide $\mathrm{pH}$ range (3-11), but when the solution is larger alkaline, the membrane will no longer apply.

\section{Conclusion}

Novel PMIA/GO composite NF membranes with higher water flux and better antifouling properties than the pristine PMIA membrane have been fabricated by first blending GO with the PMIA polymer dope, following by a phase inversion method. The incorporation of GO into the PMIA NF membrane decreased the membrane surface roughness, WCA, surface zeta potential and enhanced the membrane water flux, rejections to several dyes and antifouling properties. The $0.3 \mathrm{wt} \% \mathrm{PMIA} / \mathrm{GO}$ composite membrane showed the highest pure water flux of $125.2\left(\mathrm{~L} / \mathrm{m}^{2} / \mathrm{h}\right)$ which was nearly 2.6 times as higher as that of the pristine PMIA membrane $\left(48.3 \mathrm{~L} / \mathrm{m}^{2} / \mathrm{h}\right)$ under $0.8 \mathrm{MPa}$. In addition, the dye rejections and fouling resistance of the GO blended membranes were also higher than those of the pristine membrane. All the results show that the GO is an excellent nano-material additive which can effectively increase the water flux, rejection, and anti-fouling property of the PMIA NF membrane.

\section{Acknowledgements}

This work was supported by the National Natural Science Foundation of China (No. 21476248), and Youth Innovation Promotion Association CAS are gratefully acknowledged by the authors.

\section{References}

[1] M. Vorokhta, I. Khalakhan, M. Vaclavu, G. Kovacs, S.M. Kozlov, P. Kus, T. Skala, N. Tsud, J. Lavkova, V. Potin, I. Matolinova, K.M. Neyman, V. Matolin, Surface composition of magnetron sputtered Pt-Co thin film catalyst for proton exchange membrane fuel cells, Appl. Surf. Sci. 365 (2016) 245-251.

[2] X. Zhang, P.F. Ren, H.C. Yang, L.S. Wan, Z.K. Xu, Co-deposition of tannic acid and diethlyenetriamine for surface hydrophilization of hydrophobic polymer membranes, Appl. Surf. Sci. 360 (2016) 291-297.

[3] W.D. Zhang, C.H. Cui, Z.Q. Ren, Y. Dai, H.L. Meng, Simultaneous removal and recovery of copper(II) from acidic wastewater by hollow fiber renewal liquid membrane with LIX984N as carrier, Chem. Eng. J. 157 (2010) 230-237.

[4] H.L. Hou, J.H. Xu, Y.D. Wang, J.N. Chen, Solvent extraction performance of Pr (III) from chloride acidic solution with 2-ethylhexyl phosphoric acid-2-ethylhexyl ester (EHEHPA) by using membrane dispersion micro-extractor, Hydrometallurgy 156 (2015) 116-123.

[5] P. Li, S.S. Lim, J.G. Neo, R.C. Ong, M. Weber, C. Staudt, N. Widjojo, C. Maletzko, T.S. Chung, Short- and long-term performance of the thin-film composite forward osmosis (TFC-FO) hollow fiber membranes for oily wastewater purification, Ind. Eng. Chem. Res. 53 (2014) 14056-14064.

[6] W.P. Zhu, S.P. Sun, J. Gao, F.J. Fu, T.S. Chung, Dual-layer polybenzimidazole/polyethersulfone (PBI/PES) nanofiltration (NF) hollow fiber membranes for heavy metals removal from wastewater, J. Membr. Sci. 456 (2014) 117-127

[7] J.Q. Luo, L.H. Ding, Y.H. Wan, P. Paullier, M.Y. Jaffrin, Application of NF-RDM (nanofiltration rotating disk membrane) module under extreme hydraulic conditions for the treatment of dairy wastewater, Chem. Eng. J. 163 (2010) 307-316.

[8] W.M. Samhaber, Uses and problems of nanofiltration in the food industry, Chem. Ing. Tech. 77 (2005) 583-588.

[9] T. Chidambaram, Y. Oren, M. Noel, Fouling of nanofiltration membranes by dyes during brine recovery from textile dye bath wastewater, Chem. Eng. J. 262 (2015) 156-168.

[10] J. Huang, K.S. Zhang, The high flux poly (m-phenylene isophthalamide) nanofiltration membrane for dye purification and desalination, Desalination $282(2011) 19-26$.

[11] X.F. Sun, J. Qin, P.F. Xia, B.B. Guo, C.M. Yang, C. Song, S.G. Wang, Graphene oxide-silver nanoparticle membrane for biofouling control and water purification, Chem. Eng. J. 281 (2015) 53-59.

[12] R. Gosalawit, S. Chirachanchai, S. Shishatskiy, S.P. Nunes, Krytox-Montmorillonite-Nafion (R) nanocomposite membrane for effective methanol crossover reduction in DMFCs, Solid State Ionics 178 (2007) 1627-1635.

[13] A. Sivasankaran, D. Sangeetha, Y.H. Ahn, Nanocomposite membranes based on sulfonated polystyrene ethylene butylene polystyrene (SSEBS) and sulfonated SiO2 for microbial fuel cell application, Chem. Eng. J. 289 (2016) 442-451.

[14] H. Tang, A. Lu, L. Li, W.J. Zhou, Z.X. Xie, L.N. Zhang, Highly antibacterial materials constructed from silver molybdate nanoparticles immobilized in chitin matrix, Chem. Eng. J. 234 (2013) 124-131.

[15] B.B. Jia, J.N. Wang, J. Wu, C.J. Li, Flower-like PA6@Mg(OH)(2) electrospun nanofibers with Cr (VI)-removal capacity, Chem. Eng. J. 254 (2014) 98-105

[16] P. Han, H. Yahui, W. Yang, L. Linlin, Preparation of polysulfone-Fe3O4 composite ultrafiltration membrane and its behavior in magnetic field, J. Membr. Sci. 284 (2006) 9-16.

[17] Z.X. Wang, D.Y. Hou, S.H. Lin, Composite membrane with underwater-oleophobic surface for anti-oil-fouling membrane distillation, Environ. Sci. Technol. 50 (2016) 3866-3874.

[18] F. Bonaccorso, L. Colombo, G.H. Yu, M. Stoller, V. Tozzini, A.C. Ferrari, R.S. Ruoff, V. Pellegrini, Graphene related two-dimensional crystals, and hybrid systems for energy conversion and storage, Science 347 (2015).

[19] K.S. Novoselov, A.K. Geim, S.V. Morozov, D. Jiang, Y. Zhang, S.V. Dubonos, I.V. Grigorieva, A.A. Firsov, Electric field effect in atomically thin carbon films, Science 306 (2004) 666-669.

[20] A.K. Geim, Graphene: status and prospects, Science 324 (2009) 1530-1534.

[21] R. Mukherjee, P. Bhunia, S. De, Impact of graphene oxide on removal of heavy metals using mixed matrix membrane, Chem. Eng. J. 292 (2016) 284-297.

[22] S.J. Xia, L.J. Yao, Y. Zhao, N.N. Li, Y. Zheng, Preparation of graphene oxide modified polyamide thin film composite membranes with improved hydrophilicity for natural organic matter removal, Chem. Eng. J. 280 (2015) $720-727$.

[23] H.K. Jeong, Y.P. Lee, R.J.W.E. Lahaye, M.H. Park, K.H. An, I.J. Kim, C.W. Yang, C.Y Park, R.S. Ruoff, Y.H. Lee, Evidence of graphitic AB stacking order of graphite oxides, J. Am. Chem. Soc. 130 (2008) 1362-1366.

[24] W.W. Cai, R.D. Piner, F.J. Stadermann, S. Park, M.A. Shaibat, Y. Ishii, D.X. Yang, A. Velamakanni, S.J. An, M. Stoller, J.H. An, D.M. Chen, R.S. Ruoff, Synthesis and solid-state NMR structural characterization of (13)C-labeled graphite oxide, Science 321 (2008) 1815-1817. 
[25] R. Ding, H.Q. Zhang, Y.F. Li, J.T. Wang, B.B. Shi, H. Mao, J.C. Dang J.D. Liu, Graphene oxide-embedded nanocomposite membrane for solvent resistan nanofiltration with enhanced rejection ability, Chem. Eng. Sci. 138 (2015) 227-238.

[26] S. Bano, A. Mahmood, S.J. Kim, K.H. Lee, Graphene oxide modified polyamide nanofiltration membrane with improved flux and antifouling properties, J. Mater. Chem. A 3 (2015) 2065-2071.

[27] M. Hu, B.X. Mi, Enabling graphene oxide nanosheets as water separation membranes, Environ. Sci. Technol. 47 (2013) 3715-3723.

[28] H.R. Chae, J. Lee, C.H. Lee, I.C. Kim, P.K. Park, Graphene oxide-embedded thin-film composite reverse osmosis membrane with high flux anti-biofouling, and chlorine resistance, J. Membr. Sci. 483 (2015) 128-135.

[29] R. Rezaee, S. Nasseri, A.H. Mahvi, R. Nabizadeh, S.A. Mousavi, A. Rashidi, A. Jafari, S. Nazmara, Fabrication and characterization of a polysulfone-graphene oxide nanocomposite membrane for arsenate rejection from water, J. Environ. Health. Sci. 13 (2015)

[30] D.P. Suhas, A.V. Raghu, H.M. Jeong, T.M. Aminabhavi, Graphene-loaded sodium alginate nanocomposite membranes with enhanced isopropanol dehydration performance via a pervaporation technique, Rsc. Adv. 3 (2013) 17120-17130.

[31] J. Lee, H.R. Chae, Y.J. Won, K. Lee, C.H. Lee, H.H. Lee, I.C. Kim, J.M. Lee, Graphene oxide nanoplatelets composite membrane with hydrophilic and antifouling properties for wastewater treatment, J. Membr. Sci. 448 (2013) 223-230.

[32] N.X. Wang, S.L. Ji, G.J. Zhang, J. Li, L. Wang, Self-assembly of graphene oxide and polyelectrolyte complex nanohybrid membranes for nanofiltration and pervaporation, Chem. Eng. J. 213 (2012) 318-329.

[33] X.J. Chang, Z.X. Wang, S. Quan, Y.C. Xu, Z.X. Jiang, L. Shao, Exploring the synergetic effects of graphene oxide (GO) and polyvinylpyrrodione (PVP) on poly(vinylylidenefluoride) (PVDF) ultrafiltration membrane performance, Appl. Surf. Sci. 316 (2014) 537-548.

[34] C.Q. Zhao, X.C. Xu, J. Chen, G.W. Wang, F.L. Yang, Highly effective antifouling performance of PVDF/graphene oxide composite membrane in membrane bioreactor (MBR) system, Desalination 340 (2014) 59-66.

[35] F.M. Jin, W. Lv, C. Zhang, Z.J. Li, R.X. Su, W. Qi, Q.H. Yang, Z.M. He, High-performance ultrafiltration membranes based on polyethersulfone-graphene oxide composites, Rsc. Adv. 3 (2013) $21394-21397$.

[36] Z.H. Wang, H.R. Yu, J.F. Xia, F.F. Zhang, F. Li, Y.Z. Xia, Y.H. Li, Novel GO-blended PVDF ultrafiltration membranes, Desalination 299 (2012) 50-54.

[37] B.M. Ganesh, A.M. Isloor, A.F. Ismail, Enhanced hydrophilicity and salt rejection study of graphene oxide-polysulfone mixed matrix membrane, Desalination 313 (2013) 199-207.

[38] T. Wang, C.W. Zhao, P. Li, Y. Li, J. Wang, Effect of non-solvent additives on the morphology and separation performance of poly(m-phenylene isophthalamide) (PMIA) hollow fiber nanofiltration membrane, Desalination 365 (2015) 293-307.

[39] H. Kakida, Y. Chatani, H. Tadokoro, Crystal-Structure of poly(M-Phenylene isophthalamide), J. Polym. Sci. Part B: Polym. Phys. 14 (1976) 427-435.

[40] P. Nimmanpipug, K. Tashiro, O. Rangsiman, Factors governing the three-dimensional hydrogen-bond network structure of poly(m-phenylene isophthalamide) and a series of its model compounds (4): similarity in local conformation and packing structure between a complicated three-arm model compound and the linear model compounds, J. Phys. Chem. B 110 (2006) 20858-20864.

[41] T. Wang, C.W. Zhao, P. Li, Y. Li, J. Wang, Fabrication of novel poly(m-phenylene isophthalamide) hollow fiber nanofiltration membrane for effective removal of trace amount perfluorooctane sulfonate from water, J. Membr. Sci. 477 (2015) 74-85.

[42] Y. Yu, C.W. Zhao, L. Yu, P. Li, T. Wang, Y. Xu, Removal of perfluorooctane sulfonates from water by a hybrid coagulation-nanofiltration process, Chem. Eng. J. 289 (2016) 7-16.
[43] J.Q. Liu, A. Iranshahi, Y.C. Lou, G. Lipscomb, Static mixing spacers for spiral wound modules, J. Membr. Sci. 442 (2013) 140-148.

[44] V. Vatanpour, S.S. Madaeni, R. Moradian, S. Zinadini, B. Astinchap, Novel antibifouling nanofiltration polyethersulfone membrane fabricated from embedding TiO2 coated multiwalled carbon nanotubes, Sep. Purif. Technol. 90 (2012) 69-82.

[45] V. Vatanpour, S.S. Madaeni, R. Moradian, S. Zinadini, B. Astinchap, Fabrication and characterization of novel antifouling nanofiltration membrane prepared from oxidized multiwalled carbon nanotube/polyethersulfone nanocomposite, J. Membr. Sci. 375 (2011) 284-294.

[46] S. Bose, T. Kuila, A.K. Mishra, N.H. Kim, J.H. Lee, Dual role of glycine as a chemical functionalizer and a reducing agent in the preparation of graphene: an environmentally friendly method, J. Mater. Chem. 22 (2012) 9696-9703.

[47] S. Bose, T. Kuila, M.E. Uddin, N.H. Kim, A.K.T. Lau, J.H. Lee, In-situ synthesis and characterization of electrically conductive polypyrrole/graphene nanocomposites, Polymer 51 (2010) 5921-5928.

[48] H.L. Guo, X.F. Wang, Q.Y. Qian, F.B. Wang, X.H. Xia, A green approach to the synthesis of graphene nanosheets, Acs Nano 3 (2009) 2653-2659.

[49] D.R. Dreyer, S. Park, C.W. Bielawski, R.S. Ruoff, The chemistry of graphene oxide, Chem. Soc. Rev. 39 (2010) 228-240.

[50] J.Z. Shang, L. Ma, J.W. Li, W. Ai, T. Yu, G.G. Gurzadyan, The origin of fluorescence from graphene oxide, Sci. Rep. 2 (2012).

[51] J.H. Li, M.Z. Li, J. Miao, J.B. Wang, X.S. Shao, Q.Q. Zhang, Improved surface property of PVDF membrane with amphiphilic zwitterionic copolymer as membrane additive, Appl. Surf. Sci. 258 (2012) 6398-6405.

[52] S. Qiu, L.G. Wu, X.J. Pan, L. Zhang, H.L. Chen, C.J. Gao, Preparation and properties of functionalized carbon nanotube/PSF blend ultrafiltration membranes, J. Membr. Sci. 342 (2009) 165-172.

[53] S. Zinadini, A.A. Zinatizadeh, M. Rahimi, V. Vatanpour, H. Zangeneh, Preparation of a novel antifouling mixed matrix PES membrane by embedding graphene oxide nanoplates, J. Membr. Sci. 453 (2014) 292-301.

[54] H.Y. Zhao, L.G. Wu, Z.J. Zhou, L. Zhang, H.L. Chen, Improving the antifouling property of polysulfone ultrafiltration membrane by incorporation of isocyanate-treated graphene oxide, Phys. Chem. Chem. Phys. 15 (2013) 9084-9092.

[55] T. Szabo, E. Tombacz, E. Illes, I. Dekany, Enhanced acidity and pH-dependent surface charge characterization of successively oxidized graphite oxides, Carbon 44 (2006) 537-545.

[56] M.L. Alcaina-Miranda, S. Barredo-Damas, A. Bes-Pia, M. Iborra-Clar A. Iborra-Clar, J.A. Mendoza-Roca, Nanofiltration as a final step towards textile wastewater reclamation, Desalination 240 (2009) 290-297.

[57] X.Z. Wei, X. Kong, C.T. Sun, J.Y. Chen, Characterization and application of a thin-film composite nanofiltration hollow fiber membrane for dye desalination and concentration, Chem. Eng. J. 223 (2013) 172-182.

[58] C.H. Koo, A.W. Mohammad, F. Suja', M.Z.M. Talib, Review of the effect of selected physicochemical factors on membrane fouling propensity based on fouling indices, Desalination 287 (2012) 167-177.

[59] X.Z. Zhao, H.X. Xuan, Y.L. Chen, C.J. He, Preparation and characterization of superior antifouling PVDF membrane with extremely ordered and hydrophilic surface layer, J. Membr. Sci. 494 (2015) 48-56.

[60] A. Razmjou, J. Mansouri, V. Chen, The effects of mechanical and chemical modification of TiO2 nanoparticles on the surface chemistry, structure and fouling performance of PES ultrafiltration membranes, J. Membr. Sci. 378 (2011) 73-84.

[61] M. Ionita, A.M. Pandele, L. Crica, L. Pilan, Improving the thermal and mechanical properties of polysulfone by incorporation of graphene oxide Composites Part B 59 (2014) 133-139. 